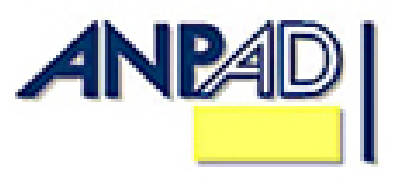

Disponível em

http://www.anpad.org.br/rac

RAC, Curitiba, v. 15, n. 1, art. 1,

pp. 1-24, Jan./Fev. 2011

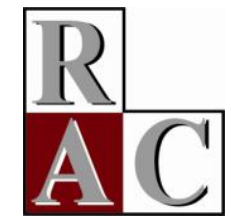

\title{
A Gestão do Desenvolvimento de Produtos na Indústria de Materiais de Construção
}

The Management of Product Development in the Construction Material Industry

Daniela Dutra da Costa * E-mail: qualidadetelhasmafrense@gmail.com Indústria de Cerâmica Vermelha Teresina, PI, Brasil.

Paulo Tromboni de Souza Nascimento

E-mail: tromboni@usp.br

Universidade de São Paulo São Paulo, SP, Brasil.

* Endereço: Daniela Dutra da Costa

Alameda Campinas, 474, apto. 43, Cerqueira César, São Paulo/SP, 01404-000.

Copyright (C) 2011 RAC. Todos os direitos, até mesmo de tradução, são reservados. É permitido citar parte de artigos sem autorização prévia, desde que seja identificada a fonte. 


\title{
Resumo
}

Essa pesquisa, qualitativa e exploratória, focou nas empresas Cecrisa e Tigre, líderes na indústria de componentes para construção, e buscou identificar o grau de formalização, as etapas da gestão do desenvolvimento de produtos e as práticas e características peculiares à IMC, cotejando-as com a literatura. Excetuadas algumas diferenças relevantes, constatou-se uma prática atualizada em relação à literatura e um processo e estrutura formais e organizados. Observou-se a predominância de projetos derivativos, em especial topológicos; diferenças na captação de ideias, com recurso à grande variedade de informações; a inserção pela Cecrisa de depoimentos de especialistas sobre a imagem da linha e a atualidade da ideia no desenvolvimento do conceito do produto, com reflexos potenciais nas suas peças promocionais. A Cecrisa se destaca ainda por montar o produto em etapas iniciais, utilizando a matéria-prima e o processo produtivo finais. As duas empresas realizam o lançamento interno do produto, distinguindo-se pela forma como é feito, o que não é tratado na literatura. As empresas estudadas recorrem à estrutura leve de projeto, pois são empresas pequenas com distâncias hierárquicas menores, onde constantemente acontecem reuniões formais e encontros informais para discussões e esclarecimentos dos projetos.

Palavras-chave: gestão da inovação; inovação componentes de edificações; lançamento interno; estrutura leve de projeto; ambiente multiprojetos.

\begin{abstract}
This qualitative and exploratory study, focusing on Cecrisa and Tigre, both leaders in the building material supply industry, attempts to identify the degree of formalization, the stages of the product development process (PDP) and the unique characteristics of the industry, comparing them with the reviewed literature. With the exception of some relevant differences, practices were up-to-date in relation to the literature and processes and structures were found to be formal and organized. Nevertheless, there are some relevant disparities. The findings of the study showed that in this sector incremental projects prevail, many oriented to topological projects. The process of capturing ideas gathers a larger amount of information, and in the concept development phase Cecrisa stands out because it includes expert opinions on the image of the product line, which may be used in its advertising. Cecrisa also stands out in the product design phase due to its development in the initial stages using raw materials and the final production process. Both companies launch their products internally, although each company does so in a different way, even though this phase is not included in the literature. These companies have lightweight projects because they are small, with smaller hierarchical distances, where formal and informal meetings are constantly held to discuss projects.
\end{abstract}

Key words: innovation management; innovation of building material supply; internal launch; lightweight project; multi project environment. 


\section{Introdução}

Desenvolver novos produtos e inovar são questões centrais também para indústrias maduras, que possuem produtos com ciclos de vida longos, tecnologia madura e demanda estável. Tidd, Bessant e Pavitt (1999) e Clark e Wheelwright (1993) acrescentam que não se trata apenas de inovar, mas de fazê-lo bem e de modo contínuo. No entanto, cabe lembrar que não existe uma melhor forma de organizar e gerenciar um projeto. Cada tecnologia, cada mercado, cada empresa exige diferentes estruturas e processos organizacionais (Tidd et al., 1999).

As indústrias da construção (IC) e a indústria de materiais de construção (IMC), que há pouco tempo se conscientizaram da importância da regulamentação e normalização de suas atividades, possuem pouca documentação que descreva e padronize o gerenciamento de projetos. Foi só em 1994, que a IC lançou mão de técnicas de gestão da construção (Souza, 2004). Essa atitude refletiu-se nos procedimentos das empresas projetistas, de consultoria e produtores de materiais e componentes. Inseriram-se, pouco tempo depois, os modelos de Gestão da Qualidade. Com isso, há poucos estudos que analisem a gestão do desenvolvimento de novos produtos (GDP) desses setores no Brasil. E quando o fazem, o tema não é central, mas acessório a outras preocupações de pesquisa.

Assim, este estudo foi dedicado à pergunta: Como é realizado o processo de gestão do desenvolvimento de um novo produto na indústria de materiais de construção (IMC)?

Convém de início realçar que a busca de literatura internacional sobre este tema, a conjugação de desenvolvimento de produtos e indústria de materiais de construção, produz muito poucos resultados relevantes. Não é claro o porquê, mas o tema não parece interessar à discussão acadêmica no hemisfério norte do planeta. Trata-se, portanto, de esforço exploratório. Primeiro, para verificar a aplicabilidade aqui de noções desenvolvidas em outros contextos empíricos. Segundo, para identificar oportunidades de pesquisa.

\section{Gestão do Desenvolvimento de Novos Produtos}

A inovação competitiva bem sucedida é muito mais que simplesmente ter boas ideias. Ela exige processo bem estruturado, com o qual a empresa pode criar novos produtos mais competitivos, em um menor espaço de tempo, com o intuito de manter ou ampliar sua participação em mercado em constante evolução (Rozenfeld et al., 2006).

Segundo Kaminski (2000), a GDP é um conjunto de atividades que envolve quase todos os departamentos da empresa e apresenta como objetivo a transformação de necessidades de mercado em produtos ou serviços economicamente viáveis. Já Rozenfeld et al. (2006, p. 3) acreditam que o processo de desenvolver produtos consiste:

em um conjunto de atividades por meio das quais se busca, a partir das necessidades do mercado e das possibilidades e restrições tecnológicas, e considerando as estratégias competitivas e de produto da empresa, chegar às especificações de projeto de um produto e de seu processo de produção, para que a manufatura seja capaz de produzi-lo.

Clark e Wheelwright (1993) afirmam que a inovação é caracterizada pela mudança tecnológica, em produtos ou em processos. Dependendo do grau de novidade, Clark e Wheelwright (1993) identificam quatro tipos de projetos de desenvolvimento de produtos e processos: Projetos incrementais ou derivativos; Projetos radicais ou breakthroughs; Projetos de plataforma ou próxima geração e Projetos de desenvolvimento avançado, também denominado Pesquisa e Desenvolvimento (P\&D). Sanderson e Uzumeri (1995), ao examinar o caso do Walkman da Sony, concluíram que a categoria de projetos incrementais incluía indevidamente um tipo adicional e numeroso de projetos: os 
topológicos, projetos cujas inovações se referem a design, pacote de funcionalidades ou facilidade de uso.

Cada projeto envolve muitas decisões. Por essa razão, torna-se necessária a organização do processo decisório de um projeto. Krishnan e Ulrich (2001) agrupam em três categorias tais decisões: estratégia e planejamento do produto; organização do desenvolvimento do produto; e gerência do projeto.

Diversos estudos indicam passos que auxiliam na GDP, apresentando formas de gerir melhor o tempo e os recursos, como organizar as pessoas e as informações, entre outras (Clark \& Wheelwright, 1993; Krishnan \& Ulrich, 2001; Rozenfeld et al., 2006).

Conforme Krishnan e Ulrich (2001) existem diferenças significativas, tanto na metodologia utilizada pelas empresas nos seus projetos de desenvolvimento, quanto na forma em que esses processos são executados. E complementam indicando que essas diferenças também existem entre projetos dentro da mesma empresa. Isso realça a dificuldade de definição de uma melhor forma para gerenciar o desenvolvimento de produtos.

Krishnan e Ulrich (2001) dividem o GDP em etapas decisórias: Desenvolvimento do conceito; Projeto da cadeia de suprimentos; Desenvolvimento do produto; Teste e validação de desempenho; e Ramp-up e lançamento. Essa divisão é didática e auxilia na identificação da interdependência dentro das fases e entre elas. Na prática, porém, o processo ocorre simultaneamente e de forma interativa, auxiliando na redução do tempo e dos custos de desenvolvimento. Os autores listam as decisões que ocorrem em cada etapa. Costa (2008) examina essas listas juntamente com sugestões de outros autores a elas pertinentes.

\section{A Indústria de Materiais de Construção}

A IMC é um dos elos que compõe a cadeia produtiva da construção. Para a Fundação Getúlio Vargas (FGV, 2006), os outros elos são: comércio atacadista e varejista; prestação de serviços técnico-profissionais, financeiros, comercialização e locação de imóveis e seguros; e a indústria da construção.

Segundo Dalcul (1994), a IC é considerada um dos mais importantes setores industriais, por ser destino final de vários outros setores. Abrange desde a atividade de construção pesada, de grandes obras de infraestrutura, à de edificações. É, por isso, de difícil análise e caracterização econômica, além da escassa informação sistematizada. Esse trabalho foca nos materiais necessários para a construção de prédios residenciais e comerciais.

A Associação Brasileira da Indústria de Materiais de Construção (ABRAMAT) e Fundação Getúlio Vargas Projetos (ABRAMAT \& FGV Projetos, 2007a) afirmam que toda a cadeia produtiva da construção iniciou o ano de 2007 com expectativas positivas. A Tabela 1 apresenta dados referentes ao valor adicionado (VA) de toda a cadeia da construção. A participação no PIB da cadeia produtiva da construção é de $8,47 \%$. A indústria de materiais de construção respondeu por $2,1 \%$ do PIB em 2004, enquanto a indústria da construção propriamente dita produziu $5,1 \%$ da riqueza nacional (Associação Brasileira da Indústria de Materiais de Construção \& Fundação Getúlio Vargas Projetos [ABRAMAT \& FGV Projetos], 2007b).

A indústria de materiais de construção teve receitas líquidas de $\mathrm{R} \$ 67,3$ bilhões em 2004. Os segmentos com produtividade média mais elevada são aqueles mais capital-intensivos: siderurgia, cimento, produção de ferro-gusa e ferro-liga e a metalurgia de metais não-ferrosos (alumínio e cobre), os quais contrastam com a produtividade mais reduzida da fabricação de produtos cerâmicos e desdobramento de madeira, por exemplo. 
Ressalvadas algumas empresas líderes, ainda é baixo o grau de conscientização quanto à adotar normas técnicas apropriadas; reduzir a cópia de produtos estrangeiros em favor do design próprio; treinar e elevar a qualificação da mão-de-obra para elevar a produtividade; modernizar a gestão empresarial e a gestão da qualidade com técnicas avançadas; e utilizar indicadores gerenciais e de competitividade (Martins, 2002).

Tabela 1

Valor Adicionado da Cadeia Produtiva da IC

\begin{tabular}{lcc}
\hline \multicolumn{1}{c}{ CADEIA PRODUTIVA } & $\begin{array}{c}\text { VA* } \\
\text { (R\$ bilhões) }\end{array}$ & \% DO VA DA CADEIA \\
\hline Construção & $84.868,0$ & 60,1 \\
Indústria de materiais de construção & $34.810,3$ & 24,7 \\
Fornecedores da indústria de materiais & $9.008,8$ & 6,4 \\
Serviços da cadeia de construção & $5.104,0$ & 3,6 \\
Comércio de materiais de construção & $7.361,8$ & 5,2 \\
TOTAL & $\mathbf{1 4 1 . 1 5 3 , 0}$ & $\mathbf{1 0 0}$ \\
\hline
\end{tabular}

Nota. Fonte: Associação Brasileira da Indústria de Materiais de Construção \& Fundação Getúlio Vargas Projetos. (2007b). A cadeia produtiva da construção e o mercado de materiais (p. 17). Recuperado em 24 agosto, 2007, de http://www.abramat.org.br/files/Estudo\%20\%20Cadeia\%20Produtiva\%20-\%20Abramat\%20.pdf

* $\mathrm{O}$ valor adicionado aqui equivale à soma dos lucros, salários e juros.

A IMC procurou inovar visando reduzir o desperdício de materiais, buscando a sustentabilidade na construção, em resposta às exigências governamentais e do mercado consumidor e à crítica ambiental. A sustentabilidade hoje é tema caro à IMC, já que a IC é grande consumidora de matériasprimas. "Estima-se que $50 \%$ dos recursos materiais extraídos da natureza estão relacionados à atividade de construção, e mais de 50\% da produção de resíduos provêm do setor ..." (Sattler, 2002, p. 220). Exemplos de produtos que incorporam o conceito de desenvolvimento sustentável são a torneira automática, que é $20 \%$ mais econômica que a convencional; a torneira eletrônica, $40 \%$; e a válvula de descarga automática, que reduz em 50\% o valor da conta de água (Coelho, 2007).

\section{Método da Pesquisa}

Esta pesquisa pode ser classificada como pesquisa qualitativa e exploratória sobre a GDP na IMC. O estudo de caso foi adotado neste estudo para levar em conta o contexto contemporâneo e permitir abrangência e detalhamento (Gil, 2007; Godoy, 1995; Yin, 2005).

Seguindo Krishnan e Ulrich (2001), a abordagem adotada nesta pesquisa focou nas decisões tomadas na GDP. Os dados foram reunidos e analisados na forma de descrição de casos. Cada descrição individual tem a seguinte estrutura: (a) Caracterização da empresa: histórico; tipo de produto; segmentação do mercado; (b) Gestão do Desenvolvimento de Produtos: conceito; estratégia e planejamento do produto; organização do desenvolvimento do produto; gerenciamento do projeto; etapas de desenvolvimento; (c) Conclusão.

$\mathrm{Na}$ análise comparativa dos casos utilizou-se uma estrutura diferente, com o intuito de facilitar a correlação das informações coletadas em cada empresa: (a) Características dos projetos de desenvolvimento de produtos; (b) Gestão do desenvolvimento de produtos: pré-desenvolvimento; desenvolvimento; pós-desenvolvimento. 
A amostra da pesquisa foi não-probabilística por conveniência, onde, para Cooper e Schindler (2003), a seleção inicial da amostragem é do pesquisador. Essa opção foi feita em parte para conseguir empresas que tivessem interesse e disponibilidade de participar e que possuíssem processos formalizados de GDP.

Foi utilizada neste estudo a adequação ao padrão que, de acordo com Yin (2005, p. 47), significa que "várias partes da mesma informação do mesmo caso podem ser relacionadas à mesma proposição teórica". Yin (2005) afirma que os diferentes padrões devem contrastar de forma clara e suficiente e que "as constatações podem ser interpretadas em termos de comparação, de, pelo menos, duas proposições concorrentes" (p. 49). As duas empresas estudadas, Tigre e Cecrisa, classificam-se em componentes, conforme categorização de Cardoso, Abiko e Gonçalves (2002).

O método de entrevista utilizado foi o não estruturado e não disfarçado. E a técnica foi a entrevista em profundidade, sem estrutura rígida predefinida de perguntas e respostas (Gil, 2007). Cada entrevista foi feita com base num roteiro de perguntas abertas, focando aspectos prescritivos e descritivos do processo de GDP. Houve duas fases distintas: uma coleta a respeito do processo de gestão da carteira de projetos, e outra referindo-se a decisões mais específicas ao desenvolvimento de um projeto. Em seguida, complementaram-se as informações coletadas com uma série de mensagens eletrônicas e telefonemas. Todas as conversas foram gravadas e devidamente anotadas no exato momento da entrevista, buscando o máximo de fidelidade aos relatos.

$\mathrm{Na}$ Cecrisa, primeiramente foi realizada uma entrevista com o Diretor Executivo e, posteriormente, com o Gerente de Produtos e Marketing Estratégico. Já na Tigre os entrevistados foram o Gerente de Produtos e Marketing, o Gerente de P\&D e o Coordenador de Oportunidades, os quais se juntaram em uma sala de reunião, apresentaram um documento interno da empresa e depois abriram espaço para discussões e complementações dos temas mais relevantes para a pesquisa.

\section{Principais Resultados}

\section{Caracterização das empresas}

\section{Cecrisa}

A Cecrisa S.A., originada na década de 1940, é uma companhia aberta que produz e comercializa porcelanatos e revestimentos cerâmicos com as marcas Portinari e Cecrisa. A empresa afirma que "Inovação e pioneirismo sempre foram fatores marcantes na vida da Cecrisa" (Diretoria Executiva). Sua história é caracterizada por pioneirismo e aquisições.

A empresa é líder na indústria e comércio de revestimentos cerâmicos. Conforme a Associação Nacional de Fabricantes de Cerâmica para Revestimento (ANFACER, 2006), existem 94 empresas nesse setor, 117 plantas industriais em 17 Estados, as quais em conjunto empregam 23 mil pessoas e possuem uma produção total de $607,9 \mathrm{~m}^{2} /$ ano. A Cecrisa possui o maior portfólio de porcelanatos do mercado nacional, o que lhe gerou um faturamento bruto anual de $\mathrm{R} \$ 497.601 \mathrm{mil}$ em 2007. É integrada por regionais de vendas instaladas nas principais cidades e capitais do País. Exporta para mais de 50 países.

Conta com 5 modernas unidades industriais, utilizando tecnologia de ponta na produção de revestimento cerâmico e porcelanato, com capacidade produtiva de $40.140 \mathrm{~m}^{2} / \mathrm{ano}$, contando com 2.199 colaboradores (Cecrisa, 2008). São elas: Portinari e Eldorado, Criciúma-SC; Cemisa, Santa Luzia-MG; Cemina, Anápolis-GO; e Incocesa, em Tubarão-SC.

A Cecrisa possui 73 coleções, ou seja, 73 linhas de produtos, e 1.200 acessórios, também denominadas de peças especiais. Em 2007, foram lançadas 11 novas coleções, contendo 272 produtos 
de fundo e acessórios. Dentre os principais estão: porcelanato, pisos, azulejos e revestimentos de fachadas.

A estratégia da Cecrisa é ser líder em lucratividade e reconhecida por: "agregar permanentemente valor aos seus clientes; usar a inovação como vantagem competitiva; e desenvolver seus profissionais" (Cecrisa, 2008a). O prêmio 'As melhores da Dinheiro', da Revista IstoÉ Dinheiro, como a Melhor Empresa em Responsabilidade Social e Meio Ambiente do Setor de Material de Construção e Decoração, "mostra que os caminhos escolhidos são sustentáveis social e ambientalmente" (Cecrisa, 2008b).

\section{Tigre}

A Tigre foi adquirida em 1941 pelo então jovem empresário João Hansen Júnior, mas só depois de alguns anos iniciou a fabricação de tubos e conexões, acessórios hidráulicos. Atualmente, exporta para 35 países, conta com 5.200 funcionários e fatura cerca de US\$ 1 bilhão. Além de líder da América Latina, lidera a fabricação de pincéis e de esquadrias em PVC no Brasil. Tem unidades fabris em Joinville (SC), Rio Claro (SP), Camaçari (BA), Castro (PR), Indaiatuba (SP) e centros de distribuição em Recife (PE) e Uruguai. Possui ainda unidades na Argentina, Chile, Paraguai, Estados Unidos, Equador, Peru, Colômbia e Bolívia (Tigre, 2007).

A Tigre enxerga a inovação sob a ótica de quem está comprando, o que se reflete na participação de $60 \%$ no mercado brasileiro de tubos e conexões. Mas a inovação também é vista como muito importante sob a ótica dos funcionários, o que, para ela, significa uma melhor empresa para trabalhar. Em 2002, a empresa foi eleita a segunda melhor empresa para se trabalhar no Brasil, e há dez anos está no ranking das 150 melhores. O gerente de P\&D da Tigre afirma que "Inovar, fazer acontecer e acreditar que é possível", é a grande bandeira desfraldada pela empresa.

O que a empresa quer transmitir por meio desses conceitos é que a inovação deve ser vista como valor, ou seja, com a inovação é possível manter-se na liderança. Hoje, conforme os entrevistados, a meta de crescimento da empresa está pautada em três pilares: novos produtos, novos negócios e novos mercados. Isso é alcançado por meio da oferta de linhas completas de produtos, identificando as necessidades do cliente e mesmo antecipando-se a elas. Em 2005, foram lançados 279 novos produtos. Com seu portfólio de mais de seis mil itens, possui soluções integrais em instalações prediais, infraestrutura e irrigação.

Essa estratégia proporcionou à empresa ocupar o $26^{\circ}$ lugar em número de patentes de empresas no Brasil, com a obtenção de, aproximadamente, 10 patentes por ano. Isso justifica os $15 \%$ do faturamento da empresa decorrente dos lançamentos nos últimos cinco anos.

\section{Processo de gestão do desenvolvimento de novos produtos}

A aderência entre os processos das empresas da IMC pesquisadas e a teoria tratou de: (a) Projetos de Desenvolvimento de Produtos; (b) Pré-desenvolvimento; (c) Desenvolvimento; (d) Pósdesenvolvimento.

A Cecrisa e a Tigre são bem semelhantes, no que diz respeito a tamanho, número de funcionários, estrutura da área de desenvolvimento e investimentos em inovação. São inovadoras e líderes de mercado, o que lhes exige boa organização na área de desenvolvimento de novos produtos. Há também diferenças na orientação de mercado das empresas estudadas. Enquanto a Cecrisa oferta seus produtos diretamente ao consumidor final, a Tigre necessita trabalhar mediante intermediários (B2B).

Observou-se que a Tigre diverge na forma de obtenção das informações, o que acarreta a necessidade de ampliação da estrutura de captação de ideias. E, mesmo com esse direcionamento, atualmente realiza pesquisas constantes com seu mercado consumidor, B2C. Por esse motivo, essa 
pequena diferença existente entre as empresas estudadas será destacada somente na análise do item pertinente.

\section{Projetos de desenvolvimento de novos produtos na IMC}

Observou-se que as duas empresas possuem áreas de pesquisa e desenvolvimento formalizadas e organizadas e desenvolvem principalmente projetos derivativos. Em seu portfólio de projetos de inovação, elas têm produtos novos para o mercado, e não apenas novos para a empresa, seja pela utilização de uma nova máquina ou equipamento, ou pelo desenvolvimento interno de um produto. Porém, os projetos topológicos (Sanderson \& Uzumeri, 1995) são a grande maioria, alimentados tanto por informações provenientes das áreas de marketing e vendas, como de adaptações ao modo de vida de seus consumidores. Já os projetos incrementais, em menor número, modificam a parte técnica dos produtos.

\section{Gestão do desenvolvimento de produtos}

Como pode ser observado na Tabela 2, cada empresa possui etapas próprias de desenvolvimento, mas se aproximam bastante da literatura de GDP. Na Cecrisa, as decisões trazidas pela literatura como essenciais para gerir o desenvolvimento de um novo produto são tomadas em momentos diferentes, de forma mais simples.

Tabela 2

Etapas de Krishnan e Ulrich (2001) versus Etapas das Empresas Pesquisadas

\begin{tabular}{ccc}
\hline & ETAPAS & \\
\hline Krishnan e Ulrich (2001) & Cecrisa & Tigre \\
\hline Pré-desenvolvimento & Levantamento e Seleção de Idéias & $\begin{array}{c}\text { Identificação de Oportunidades } \\
\text { Desenvolvimento: Projeto } \\
\text { Conceitual }\end{array}$ \\
Desenvolvimento do Conceito & Elaboração do Anteprojeto & $\begin{array}{c}\text { Desenvolvimento: Projeto } \\
\text { Preliminar }\end{array}$ \\
Projeto da Cadeia de & & $\begin{array}{c}\text { Desenvolvimento: Projeto } \\
\text { Suprimentos }\end{array}$ \\
Projeto do Produto & Desenvolvimento do Produto e Mix & Promocional \\
Teste e Validação de & Realização de Semi-industriais e \\
Desempenho & Confecção de Material Promocional & Try-out \\
Ramp-up e Lançamento & Lançamento das Coleções & Lançamento \\
Pós-desenvolvimento & Verificação da Eficácia do Lançamento & \\
& Acompanhamento dos Resultados & \\
& Comerciais & \\
\hline
\end{tabular}

Nota. Fonte: Krishnan, V., \& Ulrich, K. T. (2001). Product development decisions: a review of the literature (p. 4). Management Science, 47(1), 1-21 e dados da pesquisa.

A literatura afirma que GDP vai desde a identificação de oportunidades até sua transformação em produto disponível no mercado (Brown \& Eisenhardt, 1995; Clark \& Wheelwright, 1993; Kaminski, 2000; Krishnan \& Ulrich, 2001; Rozenfeld et al., 2006). Conforme Krishnan e Ulrich (2001) existem quatro diferentes perspectivas nas áreas de projeto e desenvolvimento: marketing, organizações, engenharia e administração da produção. Cada empresa está mais alinhada com uma ou outra perspectiva. 
A Cecrisa entende que a GDP vai desde a identificação do que o mercado quer, ou nem mesmo pensou em possuir, criando o desejo de comprar um produto. A moda e o design são fatores determinantes na decisão de compra. Porém, a tecnologia não é esquecida, seja a partir de uma matéria-prima diferente, ou da aplicação de uma tecnologia já existente e utilizada pela empresa de maneira diversa, ou ainda uma tecnologia que esteja em alta no mercado. Assim, transformam-se todas essas informações num conjunto que tenha sentido, para gerar ideias de produtos futuros.

O produto na Cecrisa é visto como um conjunto de atributos, o que está sob a perspectiva de marketing (Krishnan \& Ulrich, 2001). Duas métricas usadas são a avaliação do desempenho técnico do produto e a capacidade de inovar, sob a ótica da engenharia. A seleção de material e fornecedores e a administração do projeto são fatores críticos de sucesso na Cecrisa, caracterizando a perspectiva da administração da produção.

A GDP na Tigre está muito relacionada com a perspectiva da administração da produção, pois enxerga o produto como uma sequência de desenvolvimento (Krishnan \& Ulrich, 2001). Suas métricas de desempenho são eficiência, tempo de desenvolvimento, utilização da capacidade produtiva e custo total. Algumas variáveis de decisão são sequência e cronograma do processo de desenvolvimento, e ponto de diferenciação no processo de produção. E conta ainda com a seleção de material e fornecedores e a administração do projeto como fatores críticos de sucesso. No entanto, também enxerga seu produto como um conjunto de atributos, tendo como métricas a adequação ao mercado, a participação de mercado e a utilidade do produto para o consumidor. E um fator crítico de sucesso, que atualmente tem sido bastante explorado para seu aperfeiçoamento, é na coleta e no entendimento das necessidades dos clientes, que são características da perspectiva de marketing.

\section{Pré-desenvolvimento}

O pré-desenvolvimento engloba questões referentes à estratégia e planejamento do produto, organização do desenvolvimento do produto e gerenciamento do projeto. $\mathrm{Na}$ Tabela 3 , são indicadas todas as decisões tomadas na etapa de pré-desenvolvimento, que se repetem nos dois casos estudados.

Tabela 3

Decisões comuns à Cecrisa e Tigre - pré-desenvolvimento

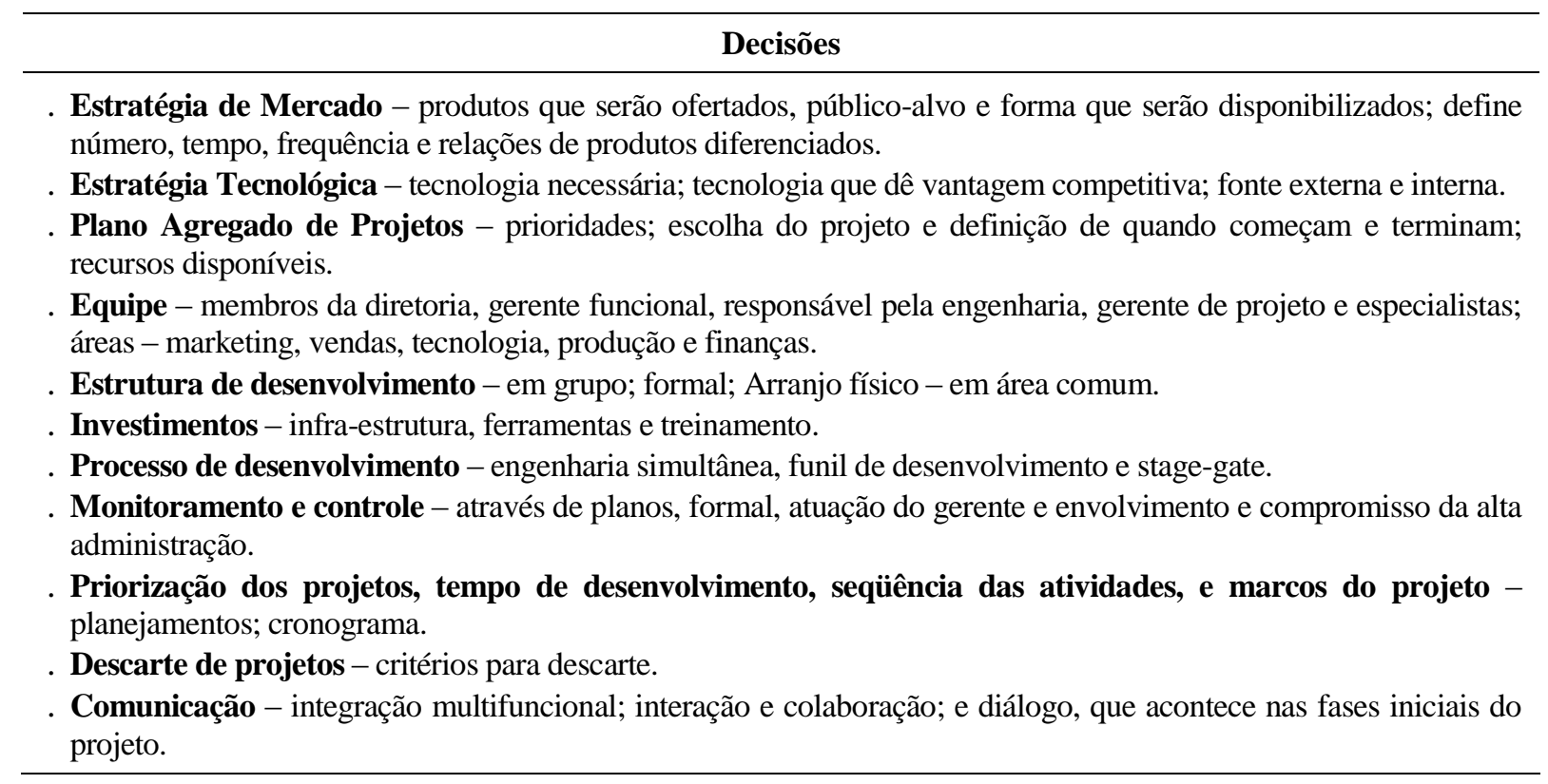

$\mathrm{Na}$ estratégia de mercado não há decisões sobre número, tempo e taxa de mudança da plataforma. Isso acontece, não por deficiência do processo, mas pela baixa aplicabilidade desta decisão 
na IMC. Afinal, os produtos da IMC permanecem no mercado por longo tempo, o que dificulta a definição prévia de quando deverá ser interrompido.

A Cecrisa e a Tigre se destacam, nessa etapa do processo, pela diversidade de insumos de desenvolvimento e pela organização e dedicação especiais. A literatura diz que se deve procurar estruturar o máximo possível essa etapa, obtendo as mais diversas informações para ampliação da boca do funil de desenvolvimento (Clark \& Wheelwright, 1993). No caso da Cecrisa, uma nova ideia pode nascer a partir de uma criação proveniente de seus profissionais ou de setores afins, que estão mais perto da moda (tecidos, móveis, eletrodomésticos), como também de novas tecnologias de matérias-primas, equipamentos e máquinas. Pode ainda surgir a partir do desenvolvimento reativo, na tentativa de reinterpretar o sucesso da concorrência internacional. É interessante notar, que a busca é feita mesmo fora de seu setor de atuação, pois se acredita que os outros setores citados exercem forte influência em seus produtos. A estratégia de mercado contém informações sobre os produtos que serão ofertados, público-alvo e forma como serão disponibilizados; e define número, tempo e relações de produtos diferenciados.

No caso da Tigre, as estratégias de mercado e tecnológica são baseadas em informações de diversas fontes. A empresa passou bastante tempo desenvolvendo novos produtos pensando na complementação de suas linhas, o que fez com que hoje tenha o maior portfólio de produtos nos três negócios em que atua. Atualmente, deixou de trabalhar orientada pelo produto, para trabalhar orientada pelo mercado. Com isso ampliou o seu programa de relacionamento com seus clientes e consumidores finais, e passou a fazer observações in loco, ou seja, vai até a casa de seus consumidores para conhecer suas reais necessidades, apesar de ser direcionada para o consumidor intermediário.

As decisões que se relacionam com o plano agregado de projetos comuns às duas empresas são as prioridades estabelecidas para escolha dos projetos, definição de quando começam e terminam, conforme os recursos disponíveis. Nesse caso, as empresas estudadas englobam todas as decisões indicadas na literatura estudada.

A definição dos projetos na Cecrisa passa por dois momentos de seleção. Primeiro, as ideias são apresentadas e discutidas em uma reunião composta por consultores, gerentes de produto e marketing estratégico, pelo pessoal da área de marketing e da área de desenvolvimento de produtos, e pelo controlador. Dessa reunião são selecionadas dez ideias, que serão apresentadas para a diretoria, e onde será definido o portfólio de novos produtos. É a partir do cronograma dos projetos, dos recursos disponíveis, do grau de inovação e do retorno financeiro que eles serão selecionados e priorizados. A maioria das mudanças propostas cuidam de design e uso, baseadas em duas fontes de informações, mercado e estilo de vida do consumidor. No entanto, há também forte presença de projetos mais ambiciosos, por eles denominados radicais (incrementais na terminologia desse texto), desenvolvidos tanto internamente, como os obtidos por meio da aquisição de novas máquinas e equipamentos.

O resultado do processo de identificação de ideias na Tigre é, cerca de 80 propostas de projetos, dos quais, após a avaliação feita pela diretoria, sobram pouco mais da metade. Para esse fim, a Tigre analisa os dados financeiros, os recursos necessários para os projetos, e o tempo de desenvolvimento. No que diz respeito à ordenação dos projetos, utiliza dados qualitativos e quantitativos, margem de contribuição, tempo de retorno do investimento, potenciais estratégicos, grau de complexidade e inovação. Seus projetos caracterizam-se como incrementais, topológicos e radicais. Os incrementais são mudanças técnicas, resultantes de algum ajuste, solicitação do cliente, facilidade de manuseio. Os topológicos caracterizam-se como modificações realizadas nos produtos, para adequação a diferentes tipos de clientes, o que ocorre com certa frequência na Tigre. E os projetos radicais são provenientes de pesquisas internas ou da aquisição de novas máquinas e equipamentos.

A literatura trata da equipe em relação à sua composição e áreas envolvidas. Nesse sentido, as empresas estudadas se preocuparam em tomar decisões essenciais que contribuíssem para o desenvolvimento de novo produto. 
A equipe de desenvolvimento na Cecrisa é composta pelas seguintes funções: controller; consultor italiano; consultora em moda e design; consultora em cerâmica; gerente de desenvolvimento do produto; gerente de produtos e marketing estratégico; e área de design. Sob a responsabilidade de cada uma das funções citadas existem pessoas que auxiliam em todo o processo, da produção, engenharia, laboratório, marketing estratégico e trade-marketing e finanças.

No caso da Tigre, sua equipe multidisciplinar tem como piso de formação o nível técnico. A equipe é formada por membros da diretoria, gerente de produto e gerente de $\mathrm{P} \& \mathrm{D}$, projetista, e especialistas das áreas de engenharia, produção, laboratório, marketing, finanças e logística, que, no entanto, não participam de todo o processo, mas são chamados quando necessário.

A estrutura de desenvolvimento em grupo e formal é comum às duas empresas. Em relação à classificação da estrutura associada ao papel da liderança, esta não se aplica à Cecrisa. Embora a Tigre tenha algumas características de peso leve na coordenação de suas equipes, esta classificação parece mais apropriada às grandes empresas das pesquisas de Clark e Wheelwright (1993), onde as distâncias hierárquicas são excepcionais, e onde as reuniões eram os únicos e raros momentos para a discussão dos projetos. Ao contrário da Tigre.

$\mathrm{Na}$ Cecrisa, a situação é um pouco diferente. Nesta designou-se uma função para controlar e servir como elo entre os projetos e a alta administração, o controller. Ele tem acesso direto e responsabilidade pelo trabalho de todos os envolvidos no projeto, é responsável por todos os projetos que estão em andamento na empresa. Encontra-se no mesmo nível do gerente de desenvolvimento de produtos e tem pouca influência na organização. É o responsável efetivo do projeto.

A estrutura da Cecrisa diferencia-se do que é apresentado pela literatura, mas funciona bem, conforme a empresa. O controller tem conhecimento profundo de todos os projetos em andamento, o que proporciona tomadas de decisão conscientes em relação à alocação de recursos, aquisições e tudo o que estiver relacionado com o planejamento agregado dos projetos. A ideia parece funcionar bem para empresas com poucos projetos em andamento.

Tanto na Tigre quanto na Cecrisa existe uma área comum para toda a equipe da área de desenvolvimento, o que facilita a comunicação, a interação e a integração. É importante ressaltar que não é uma área apenas para os membros de um projeto, mas para todas as áreas que estão diretamente relacionadas com o desenvolvimento de produtos, como engenharia, projeto, planejamento e desenvolvimento.

É nesse momento também que a literatura indica que as empresas podem definir possíveis investimentos em infraestrutura, ferramentas e treinamento. Em todas as empresas é feito um esboço do que pode ser necessário para os projetos. Consegue-se especificar bem essas informações, devido ao grau de detalhamento que é feito na identificação de oportunidades.

O processo de desenvolvimento da Cecrisa engloba conceitos da engenharia simultânea e stagegate (Cooper, Edgett, \& Kleinschmidt, 2002). A engenharia simultânea está presente, por exemplo, na etapa de Elaboração do Anteprojeto, quando, junto com o desenvolvimento do conceito, se inicia a geração de ideias do mix promocional da nova coleção. Lança-se mão do funil de desenvolvimento de Clark e Wheelwright (1993), com a finalidade de gerar um produto a partir de várias ideias, provenientes de diferentes fontes, o que corresponde ao segundo modelo.

Inicialmente a Tigre começou utilizando conceitos de como gerir o desenvolvimento de novos produtos por meio da International Organization for Standardization (ISO). Atualmente está alinhada com o Project Management Body of Knowledge (PmBok). Utiliza conceitos de GDP bastante atuais, como equipe multidisciplinar, engenharia simultânea, o funil de desenvolvimento de Clark e Wheelwright (1993) e o stage-gate de Cooper et al. (2002), que são representados pelos portões de avaliação da alta gerência para aprovação ou exclusão do projeto. No caso do funil de desenvolvimento, a Tigre trabalha com o modelo chamado inovador e focado, e sua maior característica é a expansão ao máximo da boca do funil, o que é feito com a estruturação cada vez maior da etapa de identificação de oportunidades. 
O monitoramento e controle do projeto são feitos nas empresas pesquisadas da mesma maneira, por meio de planos formais, com a atuação do gerente e envolvimento e compromisso da alta administração. Na Cecrisa e Tigre o monitoramento dos projetos é feito mensalmente pela alta administração, tendo em cada uma das empresas pessoas responsáveis pelo cumprimento do cronograma de cada projeto. No caso da Cecrisa, como já citado anteriormente, existe o controller, incumbido desta função.

A priorização dos projetos, o tempo de desenvolvimento, a sequência das atividades e os marcos de cada projeto são definidos em planos e/ou cronogramas. Na Cecrisa, analisa-se o projeto em dois polos: pelo grau de inovação e se é vendável. Em cada revisão, o projeto será analisado, pela alta administração, com base nesses dois critérios; dependendo do momento, será dado mais ênfase para um ou outro ponto.

Os critérios de seleção e priorização de projetos são essenciais para a definição de um portfólio de novos produtos bem-sucedidos. Por essa razão, as empresas devem procurar utilizar, além dos critérios quantitativos de mercado, os critérios qualitativos, caso da Tigre. Seus critérios proporcionam uma avaliação do tempo de retorno do investimento e da margem de contribuição, do potencial estratégico, do grau de complexidade e inovação. A importância do potencial estratégico se dá, pois a Tigre possui um projeto para cada produto e, frequentemente, vários projetos correspondem a uma só linha, sendo assim complementares.

A maior dificuldade, porém, está na definição de critérios confiáveis para descarte de projetos fracos, com pouca probabilidade de sucesso. Os mesmos critérios utilizados para priorização de projetos são também utilizados para descarte. Isso se deve à falta de um check list com pontos essenciais que os projetos devem ter. Na Tigre, os mesmos critérios usados para priorização dos projetos são utilizados com a finalidade de descarte.

Outro ponto de decisão nessa fase é em relação à comunicação. As duas empresas atuam da mesma forma, porém em diferentes graus. Nas etapas iniciais do processo, há uma integração maior entre o marketing e a área de desenvolvimento de produtos da empresa. Já nas etapas finais, a integração é maior com a produção. Conforme os critérios de Clark e Wheelwright (1993), é rica a comunicação na Cecrisa e Tigre: é realizada cara a cara, com a utilização de modelos gráficos, que facilitam a interação; é frequente e ocorre nos dois sentidos, ou seja, um diálogo; e acontece desde as fases iniciais do projeto. Isso se deve ao fato de serem empresas relativamente pequenas em comparação com as utilizadas na pesquisa de Clark e Wheelwright (1993).

\section{Desenvolvimento}

Nesta seção serão analisadas as etapas que fazem parte do desenvolvimento do produto. Segundo Krishnan e Ulrich (2001), as etapas são: Desenvolvimento do conceito; Projeto da cadeia de suprimentos; Desenvolvimento do produto; Teste e validação de desempenho; e Ramp-up e lançamento. A separação em estágios é bem didática e auxilia na identificação da interdependência de cada fase; no entanto, na prática o processo ocorre simultaneamente e de forma iterativa, auxiliando na redução do tempo e dos custos de desenvolvimento.

Diversos estudos indicam passos que auxiliam na GDP, apresentando formas de gerir melhor o tempo, os recursos, como organizar as pessoas e as informações, entre outros pontos relevantes para esse processo (Clark \& Wheelwright, 1993; Krishnan \& Ulrich, 2001; Rozenfeld et al., 2006).

Conforme Krishnan e Ulrich (2001) e Clark e Wheelwright (1993), existem diferenças significativas, tanto na metodologia utilizada pelas empresas nos seus projetos de desenvolvimento, quanto na forma em que esses processos são executados. E complementam indicando que essas diferenças não existem somente entre empresas, mas entre projetos dentro da mesma empresa. Isso demonstra a dificuldade de definição da melhor forma, ou mesmo da teoria ideal para desenvolver novos produtos. 
Abaixo se examina cada etapa.

\section{Desenvolvimento do conceito}

Tabela 4

\section{Decisões Comuns à Cecrisa e Tigre. Desenvolvimento do Conceito}

\begin{tabular}{l} 
Decisões \\
\hline . Interação de todos os envolvidos no processo. \\
. Clientes e consumidores finais - utilização de ferramentas para conhecer as necessidades do mercado. \\
. Escopo detalhado do produto - tecnologias disponíveis e necessárias; identificar quem é o cliente, o consumidor \\
e suas necessidades; requisitos do produto; produtos concorrentes e similares; serviços agregados ao produto; \\
objetivos ou metas que o produto deve atender; preço; e outras informações revantes para a empresa; \\
congelamento das características em etapas finais; Conceito central - technology-driven concept; design-driven \\
concept; value-driven concept; customer- and market-driven concept. \\
. Arquitetura do produto, forma física e projeto industrial - desenho virtual (Cecrisa); croqui (Tigre). \\
. Variações do produto - quais serão oferecidas, componentes compartilhados entre as variações.
\end{tabular}

A Cecrisa e a Tigre contam com a participação ampla de todos os que possam contribuir no processo desde o início dessa etapa. Smith e Reinertsen (1998) asseguram que, nessa fase inicial, a empresa deve complementar as informações, para que, mais à frente, não sejam acrescentadas informações adicionais, retardando o processo de desenvolvimento. Com essa finalidade, as empresas recorrem a ferramentas para identificar as necessidades dos clientes e consumidores finais. Porém, não inserem o consumidor nesse processo.

É nessa etapa que o projeto deve ser detalhado de forma que contenha o máximo de informações possível, a fim de auxiliar no seu desenvolvimento. As empresas estudadas identificam o cliente, o consumidor e suas necessidades, indicam os requisitos do produto, produtos concorrentes e similares, as metas a que o produto deve atender, o preço que pretendem praticar, variações do produto e componentes que serão compartilhados entre essas variações. Acrescentam ainda ao escopo do projeto informações de tecnologias disponíveis e necessárias, serviços agregados ao produto e outras informações relevantes.

A Cecrisa tem uma fórmula bastante organizada para compilar todas as informações sobre o novo projeto, o Anteprojeto. Estabelece como meta para essa etapa dar substância conceitual e mercadológica às novas linhas de produtos e integrar as várias ações a elas relacionadas. Primeiro é feita a conceituação da linha, que contém o nome, tema, relevância, funcionalidade, mercado-alvo, linguagem estética, estilo de vida, palavras-chave para associação de ideias, a imagem ícone da linha, que poderá ser utilizada nas peças promocionais da linha, se é caracterizada como inovação ou incremental, qual o diferencial, e ainda testemunhos sobre a atualidade da ideia.

Nesse mesmo documento da Cecrisa, descreve-se a estrutura da linha, com indicação do processo produtivo, as características técnicas e estéticas do produto, de seus complementos e da embalagem. Faz-se uma sondagem do mercado para identificar o potencial da linha, e analisam-se os preços dos produtos concorrentes para definição do preço do produto. Por fim, é feita a proposta inicial do mix promocional.

Na Tigre, o projeto também é bem detalhado, consequência da vasta busca de informações realizada na etapa de identificação de ideias. A área de $\mathrm{P} \& \mathrm{D}$ aperfeiçoa o projeto rapidamente, acrescentando informações sobre preço, mercado, produtos similares e complementares, componentes, investimentos, normas e patentes relacionadas ao produto, e detalhamento do consumidor e de suas necessidades. Observa-se que o cuidado no detalhamento das informações, tanto na Cecrisa quanto na Tigre, é bastante rigoroso, pois considera-se essa etapa como uma das principais. Entende-se que, com o escopo bem definido, a realização das etapas seguintes acontecerá de maneira mais simples. 
Em todas as empresas as decisões poderão ser modificadas até nas etapas finais do projeto; por isso, conforme Smith e Reinertsen (1998), deve-se procurar especificar bem o projeto, pois quaisquer modificações adicionadas posteriormente podem parecer inocentes, mas talvez adicionem complexidade e, consequentemente, mais tempo ao ciclo e custos.

A IMC parece ter como principal input o market-driven concept. No entanto, para definição do conceito central do produto, a Cecrisa e a Tigre lançam mão, também, de conceitos technology-driven, design-driven, e value-driven. E a Tigre ainda utiliza o conceito service-driven. Na literatura apresentada, identificou-se que atualmente o desenvolvimento sustentável é um dos pontos que está sendo considerado na definição dos conceitos dos novos produtos na IMC, o que pode ser confirmado pelos casos estudados.

No que se refere à arquitetura do produto, forma física, projeto industrial e variações, as empresas, de acordo com Krishnan e Ulrich (2001), podem obtê-los por meio de desenhos virtuais ou croquis. Na Cecrisa isso é alcançado por meio de desenhos virtuais, enquanto na Tigre por meio de croquis.

\section{Projeto da cadeia de suprimentos}

As atividades da fase de projeto da cadeia de suprimentos envolvem o fluxo interno e externo de materiais. A Tabela 5 apresenta todas as decisões comuns às duas empresas que se referem à etapa de Projeto da Cadeia de Suprimentos.

Tabela 5

Decisões Comuns à Cecrisa e Tigre - Projeto da Cadeia de Suprimentos

\section{Decisões}

. Componentes - projetados internamente ou comprados prontos; quem projetará, desenvolverá e produzirá.

- Cadeia de suprimentos - configuração, incluindo o local de junção dos componentes; seleção de fornecedores das tecnologias e equipamentos; sistema de produção e distribuição; custos diretos de produção; custos entre fornecimento e demanda.

Na Cecrisa a etapa de Projeto da Cadeia de Suprimentos é feita juntamente com a etapa de Projeto do Produto; porém, para a melhor compreensão, a análise foi feita nesse item. Isso aconteceu devido ao fato de a classificação de etapas adotadas no trabalho, as etapas de Krishnan e Ulrich (2001), não ser temporal, mas baseada nas tomadas de decisões dentro do processo de desenvolvimento.

Nesta etapa, a Cecrisa consegue definir muito bem quem serão seus fornecedores, quais componentes comprarão e quais serão produzidos internamente, e quem os projetará, desenvolverá e produzirá. Isso se deve ao fato de a empresa realizar nessa etapa a chamada montagem do produto, em que é realizada a prototipagem de cerâmica, simulando o processo produtivo no laboratório interno da empresa, onde já são utilizadas a matéria-prima e os equipamentos necessários para a produção da nova coleção.

No caso da Tigre, para que a área de $\mathrm{P} \& \mathrm{D}$ consiga fornecer informações reais sobre os recursos da empresa, é feita uma análise, sob a ótica da logística e planejamento, tomando por base os investimentos necessários. Nesse particular, a empresa possui equipamentos, recursos, local de armazenamento, rede de distribuição e Centro de Distribuição (CD). No fim dessa etapa, a área de $\mathrm{P} \& \mathrm{D}$ deve ter em mãos um relatório de mercado, um relatório técnico, os fluxos mapeados de todo o processo e um protótipo virtual, que contém, além das informações comuns às duas empresas, os custos diretos de produção e os custos entre fornecimento e demanda.

Convém destacar que é nessa fase que se lança mão da engenharia simultânea, em que informalmente os atores do projeto conversam entre si, para o detalhamento do projeto, adiantando 
atividades relacionadas com a etapa seguinte. Essa cultura foi introduzida na Tigre, com a finalidade de abolir as grandes reuniões, as quais só acontecem uma vez na semana com os líderes dos projetos, apenas para seu acompanhamento formal. Sempre são levados os relatórios de cada projeto, em que são repassados todos os pontos. A engenharia simultânea também proporciona um tempo menor de desenvolvimento, já que duas etapas são levadas paralelamente.

A definição dessas informações antes de passar para a etapa seguinte é de grande importância, pois possibilita à empresa o investimento e, por conseguinte, dar continuidade ao desenvolvimento, consciente de que será possível sua produção, armazenamento e distribuição.

\section{Projeto do produto}

É nessa etapa que o projeto será detalhado, com todas as informações finais para produção do novo produto.

Tabela 6

Decisões Comuns à Cecrisa e Tigre - Projeto do Produto

\begin{tabular}{l}
\hline Decisões \\
\hline Especificação dos parâmetros do projeto - projeto detalhado dos componentes; relação entre os \\
componentes do produto; seleção de material e de processo e projeto das ferramentas e equipamentos; planos \\
de processo; desenhos finais com tolerâncias. \\
. Embalagem - projeção da embalagem; planejamento do processo de embalagem. \\
. Material de suporte do produto - criação do material de treinamento e manual de instalação.
\end{tabular}

No caso da Cecrisa, todas as decisões para especificação dos parâmetros do projeto já foram concretizadas, faltando efetivar somente os testes semi-industriais. As peças produzidas servirão para a realização de testes no produto, e também como amostras para composição do mix promocional. No fim dessa etapa, o processo tecnológico e equipamentos estarão testados e aprovados, e o mix promocional pronto.

Na Tigre, a etapa Projeto do Produto é denominada Projeto Detalhado do Produto. Até esse momento foram feitos somente protótipos virtuais. No entanto, pode-se considerar como parte dessa etapa a aprovação do protótipo virtual e o desenvolvimento do protótipo em gesso. Com isso, tem-se o projeto detalhado, que será entregue à engenharia.

A projeção da embalagem e o planejamento do processo de embalagem também são decisões comuns às duas empresas. Na Tigre também se avaliam a distribuição do produto, incluindo o transporte e a entrega, e se definem as formas e sinalizações das embalagens dos novos produtos.

Vale ressaltar que na Cecrisa tudo o que se refere à embalagem começa a ser pensado desde a etapa de desenvolvimento do conceito, analisando-se facilidades para a distribuição do produto, por se caracterizar como produto de difícil manuseio, devido ao seu tamanho e peso. Na maioria das vezes, não é necessária nenhuma alteração, uma vez que os tamanhos são padronizados. Essa informação é de extrema importância, quando há constantes modificações nas embalagens dos produtos que determinada empresa comercializa. Caso essas alterações sejam pequenas, a participação de pessoas da área de embalagem pode ser postergada para etapas as finais do processo.

O material de suporte do produto comum das empresas estudadas é o manual de instalação, que não é oferecido pela literatura, e o manual do material de treinamento. São elaborados manuais completos de como realizar o treinamento para manuseio dos produtos, além de manuais que auxiliam no processo de venda do produto, fornecendo dicas de como vender e como negociar. 
Teste e validação de desempenho

Tabela 7

Decisões Comuns à Cecrisa e Tigre - Teste e Validação de Desempenho

\begin{tabular}{l}
\hline Decisões \\
\hline Prototipagem para validação - em relação a funcionamento, tamanho e fabricação; projeto industrial, \\
durabilidade, encaixe e finalização, e custos de produção. \\
. Teste em pequena escala do projeto - produção piloto; definição dos processos de produção e manutenção. \\
. Processo de construção dos protótipos - simulação virtual, prototipagem rápida; paralela; prototipagem em \\
etapas iniciais do projeto. \\
. Benefícios do protótipo - contribuem para a identificação de oportunidades; aprendizado da organização; \\
testa a comunicação entre os membros do projeto; auxilia na resolução de conflitos.
\end{tabular}

As decisões tomadas nessa etapa do processo na Cecrisa confundem-se com as decisões da etapa anterior. Krishnan e Ulrich (2001) indicam que a produção piloto deve ser feita nessa etapa, na Cecrisa, o try-out do processo é denominado de testes semi-industriais. Todas as peças que são produzidas vão para estoque e servirão de amostra para teste, de mostruário para as lojas que venderão a nova coleção, showrooms, ou seja, não serão vendidas. A etapa de try-out do projeto da Tigre deixa de ser responsabilidade da área de P\&D e passa a ser da engenharia. Esse teste é feito para que todos aprendam a manusear algum novo equipamento ou ferramenta e para verificar se o processo está pronto para ser produzido em maior escala.

É interessante perceber que os produtos produzidos nessa etapa, nas duas empresas, não são revertidos para venda, mas para a realização de testes laboratoriais, a fim de se verificar funcionamento, tamanho e fabricação, projeto industrial, durabilidade, encaixe e finalização. Além de ser utilizado para a realização de testes laboratoriais, os produtos da Cecrisa servirão também como amostra para os pontos de venda e showrooms da própria empresa.

O processo de construção dos protótipos varia de acordo com a etapa em que se encontra o projeto, podendo ser virtual, prototipagem rápida (experimentação real) ou protótipos em isopor, nas duas empresas. Ocorre concomitantemente ao processo, desde as primeiras etapas, o que proporciona às empresas diversas vantagens, no que contribui para a identificação de oportunidades, aprendizado da organização, formação de novas capacidades, além de testar a comunicação entre os membros do projeto e auxiliar na resolução de conflitos.

A Tigre afirma que os protótipos virtuais servem como meio de coleta de informações reais do projeto, pois atualmente existem programas que possibilitam sua visualização externa e interna. A empresa indica que com esse recurso conseguiram reduzir ainda mais o seu tempo de desenvolvimento, pois antes os protótipos eram feitos, nas etapas iniciais, de gesso.

\section{Ramp-up e lançamento}

$\mathrm{Na}$ etapa de ramp-up e lançamento, Clark e Wheelwright (1993) indicam a possibilidade de realizar o teste do produto no mercado, e Rozenfeld et al. (2006) indicam pontos de decisão no lançamento e ramp-up. 
Tabela 8

Decisões comuns à Cecrisa e Tigre - Ramp-up e Lançamento

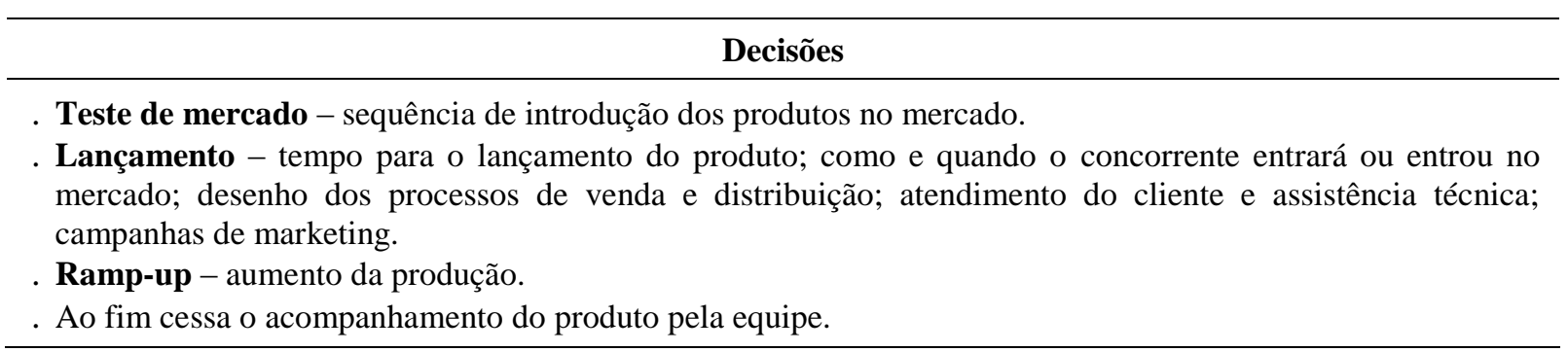

$\mathrm{Na}$ Cecrisa e na Tigre, o próprio lançamento do produto se confunde com o teste no mercado e, nesse caso, só será aumentada a produção, se o produto tiver sucesso. Com isso a empresa evita a formação de estoques inviáveis. A Cecrisa afirma que não realiza teste de mercado, pois a política da empresa é que os produtos sejam novidade para todos, até para seus funcionários.

A Tigre, além disso, possui um sistema em que todos os primeiros produtos lançados entram em quarentena e são acompanhados de perto por profissionais capacitados, para identificarem possíveis problemas nos produtos que possam ser modificados antes de saírem desse período. A vantagem desse processo é que a empresa não forma estoques de produtos que possam estar defeituosos e aproveitam para avaliar a sua aceitação no mercado.

No lançamento do produto, as decisões comuns aos casos estudados dizem respeito ao desenho dos processos de venda e distribuição, como e quando o concorrente entrará ou entrou no mercado, tempo para o lançamento do produto, atendimento do cliente e assistência técnica do produto e as campanhas de marketing.

As novas coleções da Cecrisa só serão conhecidas nas feiras e eventos do setor. Após essa primeira exposição é que os produtos serão apresentados para o pessoal interno por meio de treinamentos, através de teleconferência, gravações de DVD's com um dos consultores ministrando uma palestra sobre a nova coleção, e também com treinamentos feitos pelos consultores para arquitetos, donos de lojas, e todos aqueles que fazem parte do processo de compra final dos produtos da empresa, no Brasil.

$\mathrm{Na}$ Tigre, o lançamento é feito primeiro internamente, com a distribuição de um PDF, o qual é enviado ao pessoal de vendas da empresa, com o resumo de todo o projeto, suas vantagens, objetivos, características, preço bruto, código de barras, argumentos de venda, simulação de perguntas técnicas sobre o produto e todos os serviços que agregam o produto. Depois é feito o lançamento externo.

O ramp-up das duas empresas é feito de acordo com solicitações da área de marketing e dependerá da aceitação do produto pelo mercado consumidor. Por fim, a empresa deve procurar definir se a equipe continuará ou não acompanhando o produto no mercado (Rozenfeld et al., 2006). Tanto na Cecrisa quanto na Tigre, o acompanhamento do produto pela equipe finaliza nessa etapa.

\section{Pós-desenvolvimento}

No pós-desenvolvimento podem ser consideradas duas decisões apresentadas pela literatura pesquisada: aprendizados e melhorias para projetos futuros e avaliação do desempenho dos projetos. A Tabela 9 apresenta as decisões comuns das empresas estudadas. 
Tabela 9

Decisões Comuns da Cecrisa e Tigre - Pós-Desenvolvimento

\section{Decisões}

. Aprendizados e melhorias para projetos futuros - melhoria das capacidades envolvidas no processo e do próprio processo em si.

. Desempenho - qualidade do projeto, planejado x o que efetivamente aconteceu.

No que se refere aos aprendizados e melhorias para projetos futuros, as duas empresas estudadas procuram realizar melhorias nas capacidades envolvidas no processo e no próprio processo em si. A Tigre realiza essa atividade de forma diferenciada e que merece destaque. Logo após o lançamento, o produto entra em quarentena na Assistência Técnica. Com isso, todas as reclamações, além de serem atendidas de imediato, já são prontamente repassadas à produção com a finalidade de serem modificados os produtos que ainda serão produzidos. Por essa razão, a Tigre não forma estoque antes dessa fase de teste do produto no mercado. Outros aprendizados posteriores são utilizados em produtos futuros, podendo ser a evolução do produto para uma nova linha.

Clark e Wheelwright (1993) indicam quatro dimensões para avaliar o desempenho de projetos: tempo para colocar o produto no mercado, produtividade, qualidade do projeto e planejado versus o que efetivamente aconteceu. As duas empresas avaliam seus projetos de acordo com a qualidade, e também quanto à análise do que foi planejado versus o que efetivamente aconteceu. A Tigre vai um pouco além e mede o faturamento com produtos novos, o tempo para colocar o produto no mercado e a taxa de sucessos com o auxílio do BSC. Analisa se o que foi planejado de fato aconteceu, avaliando assim a qualidade do projeto.

A Tabela 10 apresenta, de forma resumida, todas as decisões comuns à Cecrisa e Tigre no processo de desenvolvimento de produtos.

Tabela 10

\section{Decisões Comuns à Cecrisa e Tigre}

\begin{tabular}{ll}
\hline Etapas & \multicolumn{1}{c}{ Decisões comuns à Cecrisa e Tigre } \\
\hline & Estratégia de Mercado - produtos que serão ofertados, público-alvo e forma que serão \\
& disponibilizados; define número, tempo, frequência e relações de produtos \\
& diferenciados. \\
& Estratégia Tecnológica - tecnologia necessária; tecnologia que dê vantagem \\
& competitiva; fonte externa e interna. \\
& Plano Agregado de Projetos - prioridades; escolha do projeto e definição de quando \\
& começam e terminam; recursos disponíveis. \\
& Equipe - membros da diretoria, gerente funcional, responsável pela engenharia, \\
& gerente de projeto, especialistas; áreas - marketing, vendas, tecnologia, produção e \\
& finanças. \\
Pré-desenvolvimento & Estrutura de desenvolvimento - em grupo; formal; Arranjo físico - em área comum. \\
& Investimentos - infra-estrutura, ferramentas e treinamento. \\
& Processo de desenvolvimento - engenharia simultânea, funil de desenvolvimento e \\
& stage-gate. \\
& Monitoramento e controle - através de planos, formal, atuação do gerente e \\
& envolvimento e compromisso da alta administração. \\
& Priorização dos projetos, tempo de desenvolvimento, seqüência das atividades, e \\
& marcos do projeto - planejamentos; cronograma. \\
. Descarte de projetos - critérios para descarte. \\
. Comunicação - integração multifuncional; interação e colaboração; diálogo, que \\
acontece nas fases iniciais do projeto.
\end{tabular}

Continua 


\section{Tabela 10 (continuação)}

\begin{tabular}{|c|c|c|}
\hline & Etapas & Decisões comuns à Cecrisa e Tigre \\
\hline \multirow{5}{*}{ 蒫 } & $\begin{array}{l}\text { Desenvolvimento } \\
\text { do conceito }\end{array}$ & $\begin{array}{l}\text { Interação de todos os envolvidos no processo. } \\
\text { Clientes e consumidores finais - utilização de ferramentas para conhecer as } \\
\text { necessidades do mercado. } \\
\text { Escopo detalhado do produto - tecnologias disponíveis e necessárias; identificar } \\
\text { quem é o cliente, o consumidor e suas necessidades; requisitos do produto; } \\
\text { produtos concorrentes e similares; serviços agregados ao produto; objetivos ou } \\
\text { metas que o produto deve atender; preço; e outras informações relevantes para a } \\
\text { empresa; congelamento das características em etapas finais. Conceito central - } \\
\text { input - technology-driven concept; design-driven concept; value-driven concept; } \\
\text { customer- and market-driven concept. } \\
\text { Arquitetura do produto, forma física e projeto industrial - desenho industrial } \\
\text { (Cecrisa); croqui (Tigre). } \\
\text { Variações do produto - quais serão oferecidas, componentes compartilhados } \\
\text { entre as variações. }\end{array}$ \\
\hline & $\begin{array}{l}\text { Projeto da } \\
\text { cadeia de } \\
\text { suprimentos }\end{array}$ & $\begin{array}{l}\text { Componentes - projetados internamente ou comprados prontos; quem projetará, } \\
\text { desenvolverá e produzirá. } \\
\text { Cadeia de suprimentos - configuração, incluindo o local de junção dos } \\
\text { componentes; seleção de fornecedores das tecnologias e equipamentos; sistema } \\
\text { de produção e distribuição; custos diretos de produção; custos entre fornecimento } \\
\text { e demanda. }\end{array}$ \\
\hline & $\begin{array}{l}\text { Projeto do } \\
\text { produto }\end{array}$ & $\begin{array}{l}\text { Especificação dos parâmetros do projeto - projeto detalhado dos componentes; } \\
\text { relação entre os componentes do produto; seleção de material e de processo e } \\
\text { projeto das ferramentas e equipamentos; planos de processo; desenhos finais com } \\
\text { tolerâncias. } \\
\text { Embalagem - projeção da embalagem; planejamento do processo de embalagem. } \\
\text { Material de suporte do produto - criação do material de treinamento e manual de } \\
\text { instalação. }\end{array}$ \\
\hline & $\begin{array}{l}\text { Teste e validação } \\
\text { de desempenho }\end{array}$ & $\begin{array}{l}\text { Prototipagem para validação - em relação a funcionamento, tamanho e } \\
\text { fabricação; projeto industrial, durabilidade, encaixe e finalização; e custos de } \\
\text { produção. } \\
\text { Teste em pequena escala do projeto - produção piloto; definição dos processos } \\
\text { de produção e manutenção. } \\
\text { Processo de construção dos protótipos - simulação virtual, prototipagem rápida; } \\
\text { paralela; prototipagem em etapas iniciais do projeto. } \\
\text { Benefícios do protótipo - contribuem para a identificação de oportunidades; } \\
\text { aprendizado da organização; testa a comunicação entre os membros do projeto; } \\
\text { auxilia na resolução de conflitos. }\end{array}$ \\
\hline & $\begin{array}{l}\text { Ramp-up e } \\
\text { lançamento }\end{array}$ & $\begin{array}{l}\text { Teste de mercado - sequência de introdução dos produtos no mercado. } \\
\text { Lançamento - tempo para o lançamento do produto; como e quando o } \\
\text { concorrente entrará ou entrou no mercado; desenho dos processos de venda e } \\
\text { distribuição; atendimento do cliente e assistência técnica; campanhas de } \\
\text { marketing. } \\
\text { Ramp-up - aumento da produção. } \\
\text { Ao fim cessa o acompanhamento do produto pela equipe. }\end{array}$ \\
\hline & desenvolvimento & $\begin{array}{l}\text { Aprendizados e melhorias para projetos futuros - melhoria das capacidades } \\
\text { envolvidas no processo e do próprio processo em si. } \\
\text { Desempenho - qualidade do projeto; planejado x o que efetivamente aconteceu. }\end{array}$ \\
\hline
\end{tabular}




\section{As Diferenças entre os Casos}

Seguindo a ordem lógica do processo de desenvolvimento, um ponto que deve ser destacado é o processo de captação de ideias e informações feito pela Cecrisa e Tigre. Ambas possuem uma estrutura completa e organizada. A Tigre está ainda mais à frente nesse processo de aproximação com o consumidor final, lançando mão de técnicas como a observação in loco e o processo interativo de geração de ideias.

$\mathrm{Na}$ etapa de desenvolvimento do conceito do produto, a Cecrisa se destaca pelas informações que acredita serem necessárias para iniciar o projeto. Procura, com isso, dar substância conceitual e mercadológica às novas linhas de produtos e integrar as várias ações a elas relacionadas. E traz uma novidade na busca de ideias fora do setor pela Cecrisa, para acompanhar a moda ampla, que afeta a preferência por seus produtos.

Um aspecto que merece destaque é que, nessas empresas da IMC, o desenvolvimento do conceito não é apenas orientado pelo mercado. Pelo contrário, revela elementos do que as empresas entendem serem orientações para tecnologia, design e valor, e a Tigre ainda acrescenta orientação por serviços.

Na etapa Projeto da Cadeia de Suprimentos, observou-se que a Tigre realiza um processo de obtenção de informações sobre a logística da empresa, avaliando equipamentos e recursos disponíveis, local de armazenamento, rede de distribuição e centros de distribuição, sendo única a esse respeito.

A Cecrisa se destaca no que diz respeito à montagem do produto, que se realiza em etapas iniciais do processo, com a utilização tanto da matéria-prima final, quanto do processo produtivo que será utilizado, tudo feito em laboratório interno ou nas indústrias de seus fornecedores.

Um elemento importante, referente à etapa do Projeto do Produto, na Cecrisa, sem ênfase na literatura, são os manuais de manuseio e comercialização, importantes no caso em razão do peso e dificuldade de manuseio dos produtos.

Referência deve ser feita ao lançamento interno do produto na Tigre. O lançamento interno é feito com a distribuição de um PDF, o qual é enviado para todo o pessoal de vendas da empresa, com um resumo de todo o projeto. Depois é feito o lançamento externo. Na Cecrisa, por política deliberada, o pessoal conhece o produto só quando é lançado nas feiras do setor.

$\mathrm{Na}$ etapa final a Tigre possui uma estrutura diferenciada: logo após o lançamento do produto, ele entra em 'quarentena' na Assistência Técnica. Por essa razão, a Tigre não forma estoque antes dessa fase de teste do produto no mercado. Como forma de analisar a efetividade do lançamento, vai além de outras empresas do setor, medindo o faturamento com produtos novos, o tempo para colocar o produto no mercado e a taxa de sucessos, com o auxílio do BSC.

No que se refere à estrutura associada ao papel da liderança, somente a Tigre possui características similares à estrutura peso leve (Clark \& Wheelwright, 1993). Mesmo assim, esta empresa parece desviar-se um pouco, quando comparada às imensas empresas pesquisadas por Clark e Wheelwright (1993), nas quais as distâncias hierárquicas são enormes e as reuniões eram os únicos e raros momentos para a discussão dos projetos. Equipes peso leve parecem funcionar bem em empresas de menor porte, com departamentos co-localizados. Aliás, isso também facilita a comunicação.

Clark e Wheelwright (1993) indicam três categorias de prototipagem; mas nenhuma delas se encaixa bem nas empresas estudadas. As empresas parecem obedecer a preocupações e recorrer a critérios distintos dos indicados pelos autores, mas não foi possível esclarecer se é em razão da natureza dos produtos e processos, ou do tamanho e ramo das empresas.

Por fim, deve-se observar que os projetos derivativos e topológicos (Sanderson \& Uzumeri, 1995) são predominantes neste setor. No entanto, contêm também em seu portfólio projetos novos 
para o mercado, e não apenas novos para a empresa, seja pela utilização de nova máquina ou equipamento, seja pelo desenvolvimento interno de um produto.

Tabela 11

Principais Particularidades da Cecrisa e Tigre

\begin{tabular}{|c|c|c|c|}
\hline & Etapas & Cecrisa & Tigre \\
\hline \multirow{7}{*}{ 苞 } & Pré-desenvolvimento & . Consumidor final. & $\begin{array}{l}\text { Observações in loco. } \\
\text { Processo interativo de geração de } \\
\text { idéias. } \\
\text {. Consumidor intermediário. }\end{array}$ \\
\hline & $\begin{array}{l}\text { Desenvolvimento do } \\
\text { Conceito }\end{array}$ & $\begin{array}{l}\text { Busca de idéias fora do setor. } \\
\text { Orientada pelo mercado, tecnologia, } \\
\text { design e valor. }\end{array}$ & $\begin{array}{l}\text { Orientada pelo mercado, tecnologia, } \\
\text { design, valor e serviço. }\end{array}$ \\
\hline & $\begin{array}{l}\text { Projeto da cadeia de } \\
\text { suprimentos }\end{array}$ & Montagem do produto. & . Análise da logística do projeto. \\
\hline & Projeto do produto & $\begin{array}{l}\text { Manuais de manuseio e } \\
\text { comercialização. }\end{array}$ & \\
\hline & \multicolumn{3}{|l|}{$\begin{array}{l}\text { Teste e validação de } \\
\text { desempenho }\end{array}$} \\
\hline & $\begin{array}{l}\text { Ramp-up e } \\
\text { lançamento }\end{array}$ & $\begin{array}{l}\text { Não realiza teste de mercado. } \\
\text { Lançamento externo em feiras } \\
\text { setoriais. } \\
\text { Lançamento interno só após o } \\
\text { externo. }\end{array}$ & $\begin{array}{l}\text { Lançamento interno - PDF. } \\
\text { Depois é feito o lançamento } \\
\text { externo. } \\
\text { Quarentena - assistência técnica. } \\
\text {. Não há formação de estoques. }\end{array}$ \\
\hline & Pós-desenvolvimento & & $\begin{array}{l}\text { Aprendizados e melhorias para } \\
\text { futuros projetos - quarentena. } \\
\text { Medidas de desempenho - } \\
\text { faturamento com novos produtos; } \\
\text { tempo para colocar o produto no } \\
\text { mercado; e taxa de sucessos com o } \\
\text { auxílio do BSC. }\end{array}$ \\
\hline
\end{tabular}

A Tabela 11 apresenta de forma resumida as principais particularidades dos casos pesquisados, discutidas acima.

Uma possível explicação para as diferenças entre os casos aqui tratados e a literatura talvez possa ser encontrada na lógica de agregação às linhas de produtos. São produtos de vida longa, para os quais é preciso acompanhar a reação dos consumidores antes de deliberar se e quando se vai retirá-los do mercado, o que modifica a lógica de planejamento e estratégia.

\section{Considerações Finais}

Este trabalho se propôs a identificar a formalização e as etapas da GDP, as convergências e divergências entre os casos práticos e a literatura levantada, como também as características da GDP peculiares à IMC, já realçados nas seções anteriores.

As empresas aqui retratadas, líderes de mercado da IMC no Brasil, têm procurado adequar-se às normas técnicas, reduzir a cópia de produtos estrangeiros em favor do desenvolvimento de design 
próprio, e modernizar a gestão empresarial e a gestão da qualidade com o emprego de técnicas avançadas de administração.

Porém, a inovação traz consigo muita incerteza, o que leva à busca por melhores práticas, o que exige diferentes estruturas e processos organizacionais para cada tecnologia, mercado ou empresa (Tidd et al., 1999).

Cecrisa e Tigre possuem processos formalizados, trazem conceitos e técnicas modernos e procuram constantemente atualizar-se. A Tigre é a que se encontra mais formalizada. A Cecrisa também é bem organizada, mas recorre a processos diferenciados do que se vê na literatura.

A principal limitação desta pesquisa reside em ser uma pesquisa exploratória, com amostra nãoprobabilística.

Outra limitação da pesquisa resulta das diferenças significativas nas estruturas organizacionais das empresas, na facilidade de acesso e na disposição dos entrevistados em participar do estudo. Além disso, também divergiu a forma com que foram realizadas as entrevistas.

Ainda outra limitação diz respeito às etapas de desenvolvimento. Escolheu-se trabalhar com as etapas de Krishnan e Ulrich (2001), oferecidas como síntese de vasta literatura sobre GDP. Tais etapas foram geradas a partir das decisões relacionadas, não se referindo necessariamente à ordem temporal do desenvolvimento. Com isso foi possível identificar as decisões realizadas em cada etapa dos casos. Do ponto de vista metodológico, no entanto, perde-se a estrita ordem temporal dos eventos e atividades relacionados às decisões.

Outro aspecto metodológico diz respeito ao cuidado com a divergência entre a linguagem acadêmica e empresarial. Termos como radical e incremental na linguagem das empresas, entre outros, não correspondem ao seu uso teórico.

Sugestões para trabalhos futuros incluem:

. Confirmar ou refutar os pontos aqui identificados em outras empresas da IMC.

. Realizar a mesma pesquisa nas indústrias de aglomerados e sistemas.

. Realizar estudo similar nas indústrias direcionadas para construção pesada.

- Pesquisar os fatores críticos de sucesso da GDP na IMC.

- Gerar um modelo de GDP para a IMC.

. Realizar a mesma pesquisa com empresas pequenas.

Artigo recebido em 17.03.2010. Aprovado em 06.07.2010.

\section{Referências}

Associação Brasileira da Indústria de Materiais de Construção \& Fundação Getúlio Vargas Projetos. (2007b). A cadeia produtiva da construção e o mercado de materiais. Recuperado em 24 agosto, 2007, de http://www.abramat.org.br/files/Estudo\%20\%20Cadeia\%20Produtiva\%20$\% 20$ Abramat\%20.pdf

Associação Brasileira da Indústria de Materiais de Construção \& Fundação Getúlio Vargas Projetos. (2007a). Análise setorial Abramat. Recuperado em 24 agosto, 2007, de http://www.abramat.org.br/files/Boletim\%20Analise\%20Setorial\%202_Out07(completo).pdf 
Associação Nacional de Fabricantes de Cerâmica para Revestimento. (2006). Números do setor. Recuperado em 18 fevereiro, 2008, de http://www.anfacer.org.br

Brown, S., \& Eisenhardt, K. (1995). Product development: past research, present findings and future directions. The Academy of Management Review, 20(2), 343-378.

Cardoso, L. R. A. de, Abiko, A. K., \& Gonçalves, O. M. (2002, maio). Estudo prospectivo da cadeia produtiva da construção civil no Brasil: produção e comercialização de unidades habitacionais. Anais do Encontro Nacional de Tecnologia do Ambiente Construído, Foz do Iguaçu, PR, Brasil, 9.

Cecrisa. (2008a). Intenção estratégica. Recuperado em 15 fevereiro, 2008, de http://www.cecrisa.com.br

Cecrisa. (2008b). Premios. Recuperado em 15 fevereiro, 2008, de http://www.cecrisa.com.br

Clark, K. B., \& Wheelwright, S. C. (1993). Managing new product and process development: text and cases. New York: The Free Press.

Coelho, L. (2007). Tecnologia contra o desperdício. Revista Arquitetura e Urbanismo, 22(161), 82-86.

Cooper, R. G., Edgett, S. J., \& Kleinschmidt, E. J. (2002). Optimizing the stage-gate process: what best practice companies are doing - Part II. Research Technology Management, 45(5), 1-15.

Cooper, D. R., \& Schindler, P. S. (2003). Métodos de pesquisa em administração (7a ed.). Porto Alegre: Bookman.

Costa, D. D. (2008). A gestão do desenvolvimento de produtos na indústria de materiais de construção. Dissertação de mestrado, Universidade de São Paulo, São Paulo, SP, Brasil.

Dalcul, A. L. P. C. (1994). Novas tecnologias e relações de trabalho na construção civil. Anais do Simpósio de Gestão da Inovação Tecnológica, São Paulo, SP, Brasil, 18.

Fundação Getúlio Vargas. (2006). A construção do desenvolvimento sustentado: a importância da construção na vida econômica e social do país. Recuperado em 15 junho, 2007, de http://www.fiesp.com.br/deconcic/publica\%C3\%A7\%C3\%B5es/estudo\%20final\%20da\%20unc \%20-\%202\%C2\%AA\%20edi\%C3\%A7\%C3\%A3o\%20-\%2010out06.pdf

Gil, A. C. (2007). Como elaborar projetos de pesquisa (4a ed.). São Paulo: Atlas.

Godoy, A. S. (1995). Pesquisa qualitativa: tipos fundamentais. Revista de Administração de Empresas, 35(3), 20-29.

Kaminski, P. C. (2000). Desenvolvendo produtos com planejamento, criatividade e qualidade. Rio de Janeiro: Livros Técnicos e Científicos.

Krishnan, V., \& Ulrich, K. T. (2001). Product development decisions: a review of the literature. Management Science, 47(1), 1-21.

Martins, M. G. (2002, novembro). Implantação de inovações tecnológicas no setor da construção: a visão do fornecedor. Anais do Simpósio de Gestão da Inovação Tecnológica, Salvador, BA, Brasil, 22.

Rozenfeld, H., Amaral, D. C., Forcellini, F. A., Toledo, J. C. de, Silva, S. L. da, Alliprandini, D. H., \& Scalice, R. K. (2006). Desenvolvimento de produtos: uma referência para a melhoria do processo. São Paulo: Saraiva.

Sanderson, S., \& Uzumeri, M. (1995). Managing product families: the case of the Sony Walkman. Research Policy, 24(5), 761-782. 
Sattler, M. A. (2002). Edificações e comunidades sustentáveis: atividades em desenvolvimento no NORIE/UFRGS. Anais do Seminário Ibero-Americano da Rede CYTED XIV.C, São Paulo, SP, Brasil, 4.

Smith, P. G., \& Reinertsen, D. G. (1998). Desenvolvendo produtos na metade do tempo: a agilidade como fator decisivo diante da globalização do mercado. São Paulo: Futura.

Souza, R. de (2004). Qualidade no setor da construção. In O. J. S. Oliveira (Org.), Gestão da qualidade: tópicos avançados (pp. 199-210). São Paulo: Pioneira Thomson.

Tidd, J., Bessant, J., \& Pavitt, K. (1999). Managing innovation: integrating technological, market and organizational change. England: Wiley.

Tigre. (2007). A Tigre. Recuperado em 11 outubro, 2007, de http://www.tigre.com.br/pt/institucional.php?rcr_id=7\&ctt_id=28\&uni=0

Yin, R. K. (2005). Estudo de caso: planejamento e métodos (3a ed.). Porto Alegre: Bookman. 